\title{
Vaginal treatment with lactic acid gel delays relapses in recurrent urinary tract infections: results from an open, multicentre observational study
}

\author{
Ruth Diebold ${ }^{1}\left[\right.$ (D) $\cdot$ Bettina Schopf ${ }^{2} \cdot$ Holger Stammer $^{2} \cdot$ Werner Mendling $^{3}$
}

Received: 24 November 2020 / Accepted: 17 March 2021 / Published online: 27 March 2021

(c) The Author(s) 2021

\begin{abstract}
Purpose The main objective of this open, prospective, multicentre, observational study is to investigate the relapse rate and tolerability of lactic acid gels in adult female patients with recurrent urinary tract infections during routine practice.

Methods Data were collected from patients undergoing intermittent short courses of intravaginal treatment with lactic acid gel for prevention of recurrent urinary tract infections. The observation period for individual patients was 4 months, aimed at covering four short courses of intravaginal treatment. Data on UTI relapses, tolerability, handling and satisfaction with the treatment were collected via patient diaries and physician assessments and comprised any adverse events (AEs).

Results In total, 72 patients were treated. During the last 12 months prior to the study, patients had on average 4.0 UTIs. In the 4 months after commencing treatment, $63.5 \%$ of patients had no recurrence of UTI symptoms. Overall efficacy was rated by physicians as 'excellent/good' for $96.7 \%$ of patients. The patients' overall acceptance of local treatment was high with $94.1 \%$ being '(very) satisfied'. Similarly, handling was rated as '(very) easy' by $94.2 \%$ of patients. The tolerability was assessed as 'highly tolerable/tolerable' by over $98 \%$ of patients and physicians alike. Safety analyses reported six AEs of mild intensity, all of which had resolved by the end of the study.

Conclusion Treatment with lactic acid gel may increase resilience against uropathogens, possibly preventing the need for antibiotic prevention of recurrent urinary tract infections. Treatment was positively assessed by the patients. The physician assessments corroborate these findings.
\end{abstract}

Trial registration number and date of registration DRKS00016760, 18.02.2019.

Keywords Urinary tract infection $\cdot$ Uropathogen $\cdot$ Lactic acid gel $\cdot$ Preventive treatment $\cdot$ Relapse reduction

\section{Introduction}

Urinary tract infections (UTIs) are presumably one of the most common bacterial infections [1]. Even though the prevalence is difficult to assess due to the self-limiting nature of UTIs and self-treatment, UTIs are possibly the most common urological disorder [2,3], which affects women disproportionately $[1,4]$. UTIs are clinically distinguished between

Ruth Diebold

ruth.diebold@kade.de

Dr. Kade Pharmazeutische Fabrik GmbH, Berlin, Germany

2 Pharmalog Institut für klinische Forschung $\mathrm{GmbH}$, Ismaning, Germany

3 German Centre for Infections in Obstetrics and Gynecology, Wuppertal, Germany uncomplicated and complicated cases [3]. While in uncomplicated UTIs neither structural or neurological urinary tract abnormalities, nor relevant renal disorders occur [2], complicated infections often manifest as cystitis or pyelonephritis.

By far the most common pathogen is Escherichia coli, responsible for approximately $85 \%$ of UTIs, with other pathogens such as Enterococcus faecalis, Staphylococcus saprophyticus, Klebsiella pneumoniae, Proteus mirabilis occurring considerably less frequently [5]. Recurrent UTIs (rUTIs), defined as at least three UTIs within 12 months or at least two UTIs within 6 months [6], are a great burden for the patients and have an evident, negative impact on the patients' quality of life [7-9].

The healthy vaginal microbiota is dominated by Lactobacillus species, which produce bacteriocins, surfactants, and other antimicrobial products and generally lower the vaginal pH by producing lactic acid [10]. During a UTI, Lactobacilli 
are depleted by colonization with (usually intestinal) E. coli at the vaginal introitus and periurethra. The subsequent increase of $\mathrm{pH}$ levels facilitates proliferation of $E$. coli and creates beneficial conditions for E. coli, while being more detrimental to the naturally occurring Lactobacilli, respectively [11-13].

Some treatments for rUTIs rely on probiotics, which reinoculate the microbiota with Lactobacilli to shift conditions back in favour of those lactic acid producing bacteria $[14,15]$. An alternative method is the vaginal application of lactic acid instead of Lactobacilli [16]. This fosters proliferation of the natural occurring, already present lactobacilli by lowering the $\mathrm{pH}$ level and thus restoring the natural, acidic environment.

In this observational study, lactic acid was administered as a gel in a prefilled, single-use applicator for intravaginal use [17]. Treatment occurred in short courses of 2 to 3 treatment days after each menstruation in premenopausal women and with monthly intervals in postmenopausal women. The aim of the study was to obtain real-world data on relapse prevention with a lactic acid gel in women suffering from rUTIs. Key aspects of the study were the percentage of relapses of UTIs and the tolerability of lactic acid gel as prophylaxis in adult females with uncomplicated rUTIs in daily practice. Here, we report on the results after four short courses of intravaginal treatment over 4 months of treatment.

\section{Materials and methods}

\section{Study design}

PANAMA is a multicentre, prospective, uncontrolled, single group, observational study for the prevention of relapses in rUTI with lactic acid gel (KadeFungin ${ }^{\circledR}$ Milchsäurekur). The study was performed in Germany and aimed to enrol approximately $60-80$ female patients from about 30 doctor's offices (study centres). Recruitment was anticipated to last 5 months and was planned to begin in February 2019. About two to three patients per centre were desired. Primary care physicians (general practitioners) and secondary care physicians (specialists for gynaecology and urology), who are familiar with the symptoms and treatment of acute episodes of uncomplicated rUTI, were invited to participate in the study.

The study was carried out in accordance with the ethical principles laid down in the current revision of the World Medical Association's Declaration of Helsinki as amended by the 64th General Assembly in Fortaleza in 2013 [18] and international standards for good clinical practice in medical device studies defined in ISO 14155:2011 [19]. All studyrelevant documents were submitted to the Ethics Committee (EC) responsible for the applicant/participating physician, in accordance with article 15(1) of the (Model) Professional Code for Physicians in Germany (MBO-Ä) [20] to obtain a consultation for professional rights and ethics of physicians in this study according to $\S 23 \mathrm{~b}$ of German Medical Device Law (MPG).

Women could be included in the study if they were $\geq 18$ years of age and had a medically confirmed history of recurrent acute uncomplicated urinary tract infection (i.e., $\geq 2$ UTIs within the last 6 months or $\geq 3$ UTIs within the last 12 months). A list of common risk factors associated with complicated urinary tract infection was included in the observation plan and the occurrence of these was queried. Women with asymptomatic bacteriuria were not included in the observational study. Patients were excluded from the study if they had a known hypersensitivity to any of the ingredients of KadeFungin $®$ Milchsäurekur. Although the aim of the study was to document the effect on prevention of rUTI, urinary tract infection at inclusion was not an exclusion criterion. Informed consent was obtained from all patients in the eCRF.

KadeFungin ${ }^{\circledR}$ Milchsäurekur is a non-prescription CEcertified medical device class IIa filled with lactic acid gel for intravaginal application. With a $\mathrm{pH}$ value of four it resembles the optimal natural physiological condition. Thereof it is intended for regeneration and stabilization of the vaginal microbiota. With each applicator, $2.5 \mathrm{ml}$ lactic acid (corresponding to $150 \mathrm{mg}$ of S-lactic acid) is released deep into the vagina. Recommendation is to use one applicator filling once daily before bedtime for 2 to 3 days after each menstruation/in monthly intervals.

Demographic and baseline characteristics were recorded: age (years), year of birth, confirmation of female gender and inclusion diagnosis, number of UTIs during the 12-month period prior to visit D1 (including current episode of UTI, if applicable), previous treatment of rUTIs, other current medical conditions/treatment (antibiotics or other) related to UTI), dispense of diary.

Patients were asked to keep a monthly diary for 4 months after D1 on the following aspects: occurrence of UTI in the previous month (medical confirmation of UTI was not explicitly required), onset/end of UTI (if occurred), how the UTI was treated (antibiotics or others) and use of KadeFungin ${ }^{\circledR}$ Milchsäurekur according to instructions for use (yes/no). After the 4-month treatment period, they rated once the treatment satisfaction (rating options: very satisfied, satisfied, moderately satisfied, dissatisfied), the product handling (rating options: very easy, easy, moderate, difficult), the additional moisturisation (rating options: very pleasant, pleasant, neutral, unpleasant, very unpleasant) and the local tolerability of KadeFungin ${ }^{\circledR}$ Milchsäurekur (rating options: highly tolerable', 'tolerable', 'moderately tolerable', 'intolerable'). In addition, all adverse events were recorded. If there was no face-to-face visit, the patient could be asked 
to return the diary to the physician by post, or the physician could conduct a phone call and request the information in the diary, otherwise the patient was counted as lost to follow-up.

An optional visit D2 (approximately 4 months, but no later than 4.5 months after D1) could be performed to assess the patient's health status, including a vulvovaginal examination with $\mathrm{pH}$ measurement (optional), as well as assessment of local tolerability (rating options: 'highly tolerable', 'tolerable', 'moderately tolerable', 'intolerable') and presence or absence of erythema, oedema, vulvovaginal itching, others (specify).

After contact with the patient, the physician was asked to indicate whether an assessment of tolerability/efficacy was possible. The assessment of tolerability/efficacy ranged from excellent, good, moderate, bad and very bad.

In accordance with the design of the study, the measurement of vaginal $\mathrm{pH}$ at $\mathrm{D} 1$ and $\mathrm{D} 2$ was left to the decision of the treating physician.

The primary endpoint of the study was the $\%$ of patients without UTI-relapse within 4 months after visit D1 based on diary data. Secondary endpoints with regard to efficacy were the $\%$ of patients without relapse within 1, 2 and 3 months after visit D1, time to first relapse, number of relapses within 4 months after $\mathrm{D} 1$, mean change of vaginal $\mathrm{pH}$ value from baseline to D2, physicians' global judgments of efficacy, patients' assessments of treatment satisfaction, patients' assessments of additional moisturizing effect, patients' adherence to the mode of application described in the user manual, and patients' assessments of product handling. Secondary endpoints with regard to safety and tolerability were the type, frequency and severity of adverse events (AEs), adverse device effects (ADEs) or device deficiencies [21], patients' judgments of local tolerability and physicians' global judgements of tolerability.

\section{Statistics}

Population required to demonstrate a relevant effect in relation to the primary endpoint was calculated using the PASS 11 sample size software [22]. In case of clinically relevant patient benefit from the application of the gel, a sample size of 60-80 patients is sufficient to estimate these effects with adequate statistical precision, i.e., $\pm 10 \%$ in the $90 \%$ confidence interval range for the primary end point. Depending on the scope of the analysis, different patient datasets were used. The safety analysis set (SES) included all patients who administered the medical device under investigation and for whom any post-baseline safety data were documented in the diary and/or eCRF. The full analysis set (FAS) included all patients of the SES who documented any post-baseline information on the reoccurrence of UTI in the diary. The complete case (CC) cohort included all patients of the FAS who documented four treatment courses in the diary (one course per month) and had an individual observation time of $\geq 106$ days ( $=4$ months -2 weeks tolerance as period between date of visit D1 and date of patient's last entry in the diary). Primary and secondary endpoints were analysed using the FAS and CC cohort. Safety endpoints were evaluated using the SES. If applicable, 95 and $90 \%$ Wilson confidence intervals were calculated for primary endpoint analysis. Comparison of subgroup categories was performed using the Fisher's exact test for $2 \times 2$ categorical data. In the following description of results, $N$ describes the total number of patients, $N_{\text {valid }}$ represents the number of patients with valid observations and $n$ the respective observed frequencies counted for the described event.

\section{Results}

In total, 78 women with rUTI were enrolled in the study. For reasons unrelated to treatment, six patients were excluded from the safety analyses set (SES: $N=72,100 \%$ ), as well as two from the full analysis set (FAS: $N=70,100 \%$ ). Another 16 patients were excluded from the $\mathrm{CC}$ cohort. (CC cohort: $N=54,100 \%$ ) (Fig. 1).

Two third of patients were less than 50 years old (66.7\%). In the SES the \% with 2-3 UTIs was 48.6, 4-5 UTIs occurred in $34.7 \%$ and six or more in $16.7 \%$, with a mean number of 4.0 UTIs (SD 1.9; range 2-10 UTIs). Risk factors associated with a complicated UTI were not reported for any of the 72 patients at baseline.

Fifty one patients $(70.8 \%)$ had been treated with antibiotics (48 patients, $66.7 \%$ ) or herbal medicine (3 patients $4.2 \%$ ) during the 3-month period prior to visit D1. Concomitant medication for acute UTI at inclusion was used in eight (11.1\%) (Table 1). During the 4-month observation period, patients did not document any concomitant medication.

The median study duration was 126.0 days (range 79-179 days) for both the SES $\left(N_{\text {valid }}=71\right)$ and the FAS $(N=70 ; 100.0 \%)$. In the CC cohort, the median study duration was 126.0 days (range 119-145 days). The maximum study duration of 179 days was recorded for one patient. The mean number of treatment courses within 4 months was 3.6 (SD 1.0) in the SES, 3.7 (SD 0.8) in the FAS and 4.0 (SD 0.0) in the CC cohort. The \% of treatment-compliant patients was over $90 \%$. Sixty three patients $(94.0 \%)$ were treatment-compliant in the FAS $(94.0 \%$ of 67 patients with non-missing data) and all 54 patients (100\%) in the CC cohort (treatment-compliant patients used KadeFungin ${ }^{\circledR}$ Milchsäurekur once per month over 4 months).

In the FAS ( $\left.N_{\text {valid }}=63\right), 63.5 \%$ of patients had no relapse of UTI symptoms within 4 months (95\% Wilson CI between 51.2 and $74.3 \%)$. In the $\mathrm{CC}$ cohort $(N=54)$, it was $72.2 \%$ of patients (95\% Wilson CI between 59.1 and $82.4 \%$ ). The proportion of relapse-free patients in the FAS decreased from 


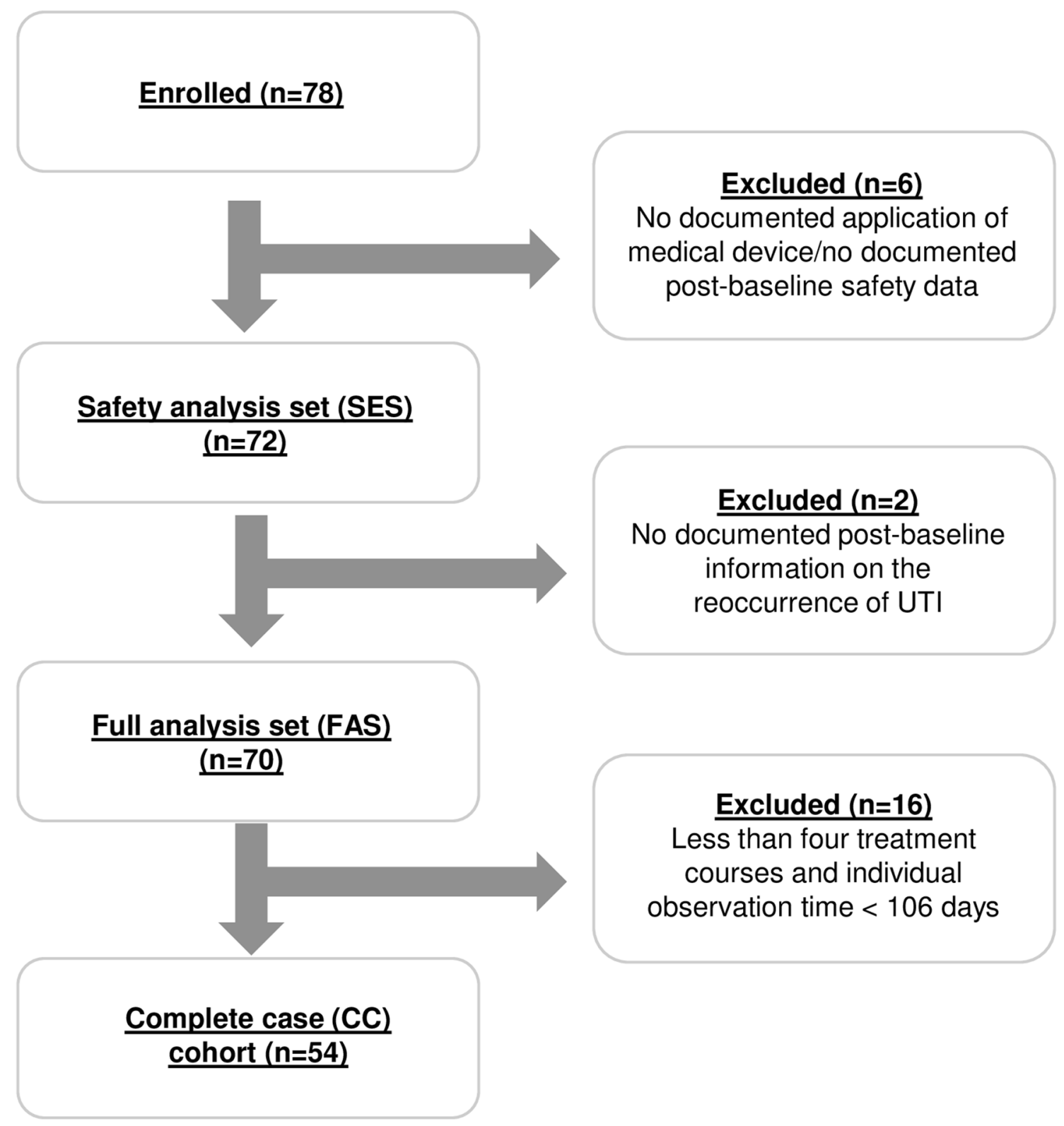

Fig. 1 Patient flow chart and analysis sets

Table 1 Concomitant medication for acute UTI at inclusion reported at visit D1 (SES)

\begin{tabular}{lc}
\hline & $\begin{array}{l}\text { Number }(\%) \\
\text { of patients }\end{array}$ \\
\hline $\begin{array}{l}\text { Total patients in the SES } \\
\text { Total patients with concomitant medication for acute } \\
\text { UTI at inclusion }\end{array}$ & $82(100 \%)$ \\
Medication as reported in the eCRF & \\
Ciprobay 500 & $11.1)$ \\
Ciprofloxacin 250 & $1(1.4)$ \\
Antibiotics (not specified) & $1(1.4)$ \\
Nitrofurantoin & $4(5.6)$ \\
Fluomizin & $1(1.4)$ \\
\end{tabular}

$85.7 \%$ after the first month, to 76.8 and $69.1 \%$ after the second and third month, respectively (FAS, $N_{\text {valid }}=70 / 69 / 68$, $100 \%)$. The corresponding values in the $\mathrm{CC}$ cohort were 90.7, 83.3 and 75.9\% (CC, $N=54,100 \%$ ) (Table 2, Fig. 2).

For patients that had at least one relapse of UTI symptoms in the 4-month observation period (FAS, 36.5\%), the mean time to first relapse was 46.8 days, which had a high variance (median 41 days, range 8-116 days).

Subgroup analyses based on baseline characteristics showed no evidence that the $\%$ of patients being relapsefree after 4 month(s) differed by patient age (categories $18-49 ; \geq 50$ years) or the number of UTIs in the previous 12 months (categories $2-3 ; 4-5 ;>6$ UTIs). The two-sided $p$ 
Table 2 Proportion of patients with and without relapse and 90/95\% Wilson confidence intervals (FAS, CC cohort) within 4 months after D1

$\begin{array}{lll}\text { Patients } N(\%) & \begin{array}{l}\text { Binominal } \\ \text { proportion }\end{array} & \begin{array}{l}95 \% \text { Wilson confidence } \\ \text { interval }\end{array}\end{array}$

Lower limit Upper limit

Without relapse within 4 months after D1 (primary endpoint)

FAS $\left(N_{\text {valid }}=63\right)$

$\begin{array}{lllll}\text { Yes } & 40(\mathbf{6 3 . 5}) & 0.635 & 0.5115 & 0.7428 \\ \text { No } & 23(36.5) \\ \text { CC cohort }(N=54,100 \%) & & & \\ \text { Yes } & 39(\mathbf{7 2 . 2}) & 0.722 & 0.5911 & 0.8238 \\ \text { No } & 15(27.8)\end{array}$

Without relapse within 3 months after D1 (secondary endpoint)

FAS $\left(N_{\text {valid }}=68\right)$
Yes $47(\mathbf{6 9 . 1})$
No $\quad 21(30.9)$
CC cohort $(N=54,100 \%)$
Yes $41(\mathbf{7 5 . 9})$
No $13(24.1)$

Without relapse within 2 months after D1 (secondary endpoint)

FAS $\left(N_{\text {valid }}=69\right)$
Yes $53(\mathbf{7 6 . 8})$
No $\quad 16(23.2)$

Without relapse within 1 month after D1 (secondary endpoint) FAS $(N=70,100 \%)$

\begin{tabular}{|c|c|c|c|c|}
\hline Yes & $60(85.7)$ & 0.857 & 0.7566 & 0.9205 \\
\hline No & $10(14.3)$ & & & \\
\hline \multicolumn{5}{|c|}{ CC cohort $(N=54,100 \%)$} \\
\hline Yes & $49(\mathbf{9 0 . 7 )}$ & 0.907 & 0.8009 & 0.9598 \\
\hline No & $5(9.3)$ & & & \\
\hline
\end{tabular}

values of the Fisher's exact test calculated for the FAS were all $>0.05$ (Table 3).

The same applied to the CC cohort (data not shown). When interpreting the results of the subgroup analyses, it needs to be considered that the sample size of the compared subgroup categories were unequal and different sample sizes may have influenced the $p$ values.

Only three patients (4.3\%) had vaginal $\mathrm{pH}$ at both $\mathrm{D} 1$ and D2. The mean change in D1 was -2.1 (SD 1.2; range -3 to -1$)$. Due to the very small sample analysed, the result is not meaningful.

Physicians rated the overall efficacy as 'excellent/good' for $96.7 \%$ of patients $(n=58)$, as 'moderately effective' for $1.7 \%(n=1)$, and as 'bad' for $1.7 \%(n=1)\left(\right.$ FAS: $\left.N_{\text {valid }}=60\right)$. The patients' overall acceptance of local treatment with KadeFungin® Milchsäurekur was high. 94.1\% $(n=64)$ of patients were '(very) satisfied' and 5.9\% $(n=4)$ 'moderately satisfied' (FAS: $N_{\text {valid }}=68$ ). Similarly, handling was rated as '(very) easy' by $94.2 \%(n=65)$ of patients and as 'moderate' by $5.8 \%(n=4)$ (FAS: $\left.N_{\text {valid }}=69\right)$. The additional moisturizing effect was rated was '(very) pleasant' by $72.5 \%(n=50)$ of patients, as 'neutral' by $24.6 \%(n=17)$, and as 'unpleasant' by $2.9 \%(n=2)$ (FAS: $\left.N_{\text {valid }}=69\right)$.

All AEs that occurred during the study were of mild intensity. No serious AEs were recorded. In total, 4 of the 72 patients in the SES (5.6\%) experienced 6 AEs, thereof $1.4 \%$ with an ADE (mild application site pruritus) (Table 4). All six AEs had resolved by the end of the study.

The local tolerability of KadeFungin ${ }^{\circledR}$ Milchsäurekur was rated as 'highly tolerable/tolerable' by $98.6 \%(n=68)$ of patients and as 'moderately tolerable' by $1.4 \%(n=1)$ (FAS: $N_{\text {valid }}=69$ ). Physicians rated the overall tolerability of the treatment as 'excellent /good' for $98.4 \%(n=61)$ of patients and as 'moderately tolerable' for $1.6 \%(n=1)$ (FAS: $N_{\text {valid }}=62$ ).

\section{Discussion}

To our knowledge, this is the first study to observe a preventive effect of a vaginal lactic acid gel in a larger group of women with a history of uncomplicated rUTIs during routine practice. The results suggest that vaginal lactic acid gel can reduce the rate of rUTIs when used for a short period every month. $66.7 \%$ of women had no further UTIs after a period of 4 months.

Uncomplicated rUTI in women is thought to arise from repeated ascending infection of the bladder by intestinal bacteria (usually $E$. coli) that colonise the vaginal vestibule and distal urethra in large numbers [10, 23, 24]. Vaginal culture studies have shown that women with rUTI also show a tendency to vaginal colonisation with $E$. coli during the asymptomatic periods [25]. Application of a vaginal lactic acid gel for short monthly courses with an appropriately amount of lactic acid could therefore not only favour beneficial Lactobacillus-dominated microbiota [26], but also limit the growth of $E$. coli by creating unfavourable growth conditions. Hudson et al. [27] investigated the relative effects of $\mathrm{pH}$ and lactic acid concentration on $E$. coli growth and were able to show a direct correlation.

There are different opinions about which is the most important antimicrobial factor produced by Lactobacilli: some groups describe that women with rUTI are deficient in $\mathrm{H}_{2} \mathrm{O}_{2}$-producing Lactobacilli [25, 28, 29], others describe lactic acid as the even more important antimicrobial factor [30]. Under the hypoxic conditions that prevail in the vagina, Lactobacilli would produce little or no $\mathrm{H}_{2} \mathrm{O}_{2}$. [30] Lactic acid was also shown to be a strong outer membrane disintegrating as well as permeabilising agent of gram-negative bacteria 


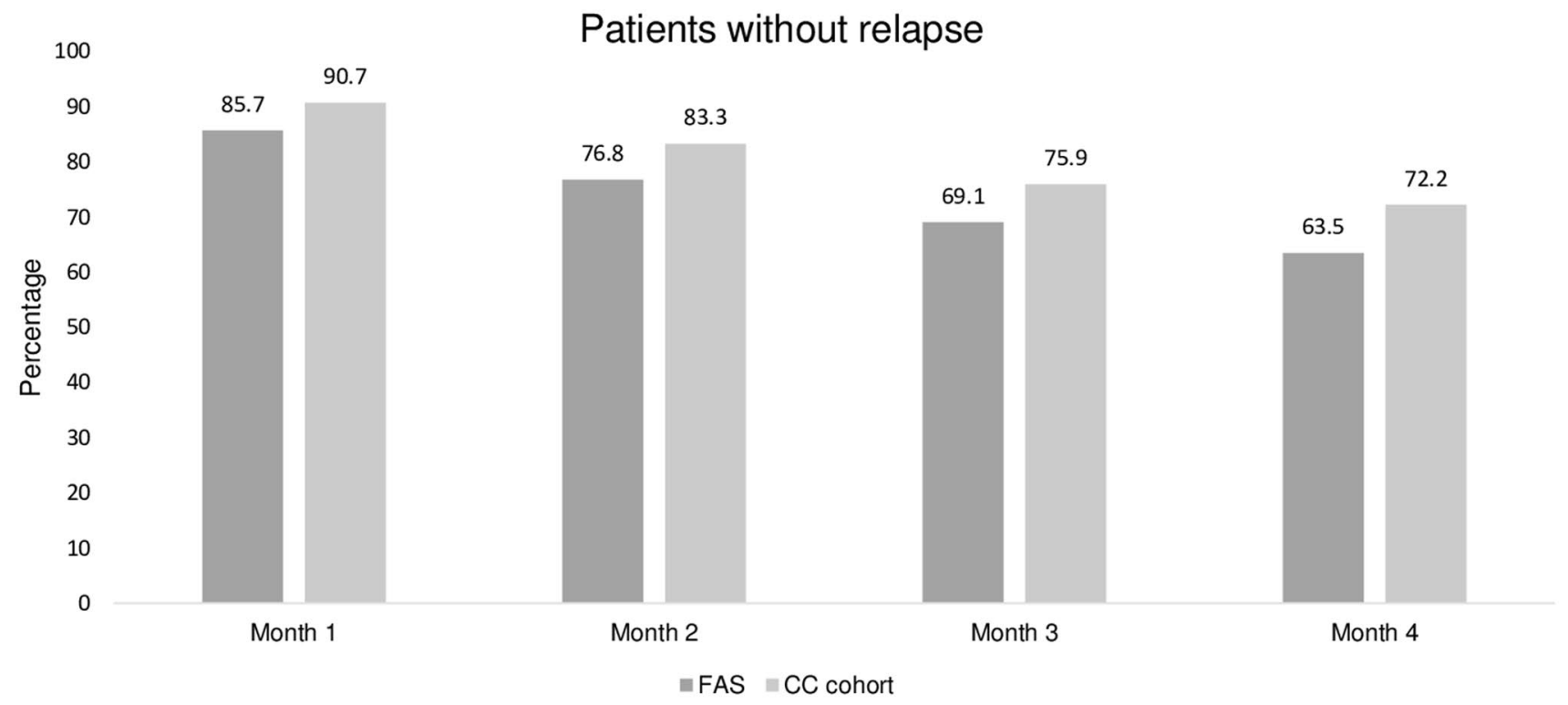

Fig. 2 Percentage of patients with no relapse of UTI during 1, 2, 3 and 4 months of observation in FAS $\left(N_{\text {valid }}=70 / 69 / 68 / 63\right.$, for periods of 1 , 2, 3 and 4 months) and $\mathrm{CC}$ cohort ( $N=54,100 \%$ for all periods)

Table 3 Subgroup analyses by baseline characteristics (previous UTIs and age)

\begin{tabular}{|c|c|c|c|c|c|c|}
\hline \multirow[t]{2}{*}{$\begin{array}{l}\text { Subgroups } \\
\text { by category }\end{array}$} & \multirow[t]{2}{*}{$\begin{array}{l}\text { Total patients } \\
\text { per category }\end{array}$} & \multirow{2}{*}{$\begin{array}{l}\text { Patients with- } \\
\text { out relapse } N \\
(\%)\end{array}$} & \multirow[t]{2}{*}{$\begin{array}{l}\text { Binominal } \\
\text { proportion }\end{array}$} & \multicolumn{2}{|c|}{$\begin{array}{l}\text { 90/95\% Wilson confi- } \\
\text { dence interval }\end{array}$} & \multirow[t]{2}{*}{ Fisher's exact tes } \\
\hline & & & & Lower limit & Upper limit & \\
\hline \multicolumn{7}{|c|}{ Number of UTIs during the past 12 months } \\
\hline $2-3$ & 34 & $22(64.7)$ & 0.647 & $\begin{array}{l}0.5060 \\
0.4791\end{array}$ & $\begin{array}{l}0.7664 \\
0.7851\end{array}$ & \multirow{3}{*}{$\begin{array}{l}{ }^{\mathrm{a}} 0.7691 \\
{ }^{\mathrm{b}} 0.1975 \\
{ }^{\mathrm{c}} 0.2348\end{array}$} \\
\hline $4-5$ & 21 & $15(71.4)$ & 0.714 & $\begin{array}{l}0.5353 \\
0.5004\end{array}$ & $\begin{array}{l}0.8444 \\
0.8619\end{array}$ & \\
\hline$\geq 6$ & 8 & $3(37.5)$ & 0.625 & $\begin{array}{l}0.1612 \\
0.1368\end{array}$ & $\begin{array}{l}0.6520 \\
0.6943\end{array}$ & \\
\hline \multicolumn{7}{|l|}{ Age [age] } \\
\hline $18-49$ & 41 & $30(73.2)$ & 0.732 & $\begin{array}{l}0.6062 \\
0.5807\end{array}$ & $\begin{array}{l}0.8285 \\
0.8431\end{array}$ & \multirow[t]{2}{*}{${ }^{\mathrm{d}} 0.0532$} \\
\hline$\geq 50$ & 22 & $10(45.5)$ & 0.455 & $\begin{array}{l}0.2947 \\
0.2692\end{array}$ & $\begin{array}{l}0.6244 \\
0.6534\end{array}$ & \\
\hline
\end{tabular}

Number (\%) of patients without relapse within 4 months after D1 and $p$ values for the Fisher's exact test $\left(\right.$ FAS: $\left.N_{\text {valid }}=63\right)$

${ }^{\text {a }} p$ value for the comparison of UTI categories ' $2-3$ ' versus ' $4-5$ ',

${ }^{\mathrm{b}} p$ value for the comparison of UTI categories ' $4-5$ ' versus ' $\geq 6$ '

${ }^{c} p$ value for the comparison of UTI categories ' $2-3$ ' versus ' $\geq 6$ '

' $p$ value for the comparison of age categories ' $18-49$ ' versus ' $\geq 50$ '
[31]. Swidsinski et al. [16] have demonstrated a positive effect of a vaginal lactic acid gel on acute $E$. coli cystitis. With a 4-week treatment period, not only the clinical symptoms disappeared in more than half of the patients, but also a bacteriostatic effect including morphological changes could be observed. Antibiotic treatment was not necessary. These results support our assumptions that vaginally applied lactic acid can limit $E$. coli growth and thus prevent a transfer of the uropathogen from the vagina to the urinary bladder. The research group did not find any preventive effect of lactic acid, but the study was focused on acute treatment and only a few patients used the vaginal gel for relapse prevention.

The effect of vaginal administration of lactic acid preparations to restore an optimal microbiota has mainly been shown for the treatment of bacterial vaginosis, in combination with an antibiotic or as single therapy [32-35]. Two recently published systematic review articles conclude that, despite methodological limitations and the need for large, rigorous 
Table 4 Overview of adverse events/adverse device effects reported during the observation period (SES: $N=72,100 \%$ )

\begin{tabular}{lll}
\hline & Event(s) $n$ & $\begin{array}{l}\text { Patient(s) with at } \\
\text { least one event } N \\
(\%)\end{array}$ \\
\hline Total AEs/ADEs/patients with AEs/ADEs & & $\mathbf{4}(\mathbf{5 . 6})$ \\
AE (MedDRA) without causality to the medical device & & $\mathbf{2 ( 2 . 8 )}$ \\
Infections and infestations & $\mathbf{2}$ & $1(1.4)$ \\
Cystitis (mild) & 1 & $1(1.4)$ \\
Subcutaneous abscess (mild) & 1 & $\mathbf{2}(\mathbf{2 . 8})$ \\
Musculoskeletal and connective tissue disorders & $\mathbf{2}$ & $1(1.4)$ \\
Mobility decreased (mild) & 1 & $\mathbf{2}(\mathbf{2 . 8})$ \\
Psychiatric disorders & $\mathbf{2}$ & $1(1.4)$ \\
Insomnia (mild) & 1 & $1(1.4)$ \\
Nervousness (mild) & 1 & $\mathbf{1}(\mathbf{1 . 4})$ \\
AE with causality to the medical device (ADE & & $1(1.4)$ \\
General disorders and administration site condition & & $\mathbf{1}$ \\
Application site pain possible (mild) & 1 & \\
\end{tabular}

randomised trials, vaginal lactic acid preparations are effective in the treatment of BV and can thus be considered as an alternative to antibiotics such as metronidazole [36, 37]. Comparable to our study, no major safety concerns were reported and the preparations were well tolerated [36]. While in our study, one woman experienced pain at the application site that was assessed as possibly related to the vaginal gel, women in the BV studies reported vaginal or vulvar irritation, itching, burning, redness and/or dryness [36].

Another non-antimicrobial, well-tolerated treatment option for the prevention of UTIs is the vaginal or oral use of probiotics mainly as Lactobacillus spp [15, 38-42]. Probiotics may prevent bladder invasion by inducing an immune response via the urethra or vagina and by colonising the vagina with beneficial bacteria. Furthermore, the antimicrobials might interfere with uropathogens [42]. Various effects of different strains on the growth or adhesion of uropathogens have been shown in in vitro studies [43, 44]. Lactobacillus brevis DT 24 was identified to produce a bacteriocin (Bacteriocin DT24), which effectively inhibits the growths of various pathogens [45]. The strain Lactobacillus reuteri CRL 1324 reduced the adhesion and internalisation of E. coli 275 into HeLa cells [46]. Under optimal conditions for lactic acid production, Lactobacillus acidophilus CRL 1259 inhibited the growth of $E$. coli.[47] Various strains have been investigated in randomised controlled or non-controlled trials over the past decades for their efficacy in preventing urinary tract infections. Despite the promising in vitro results [39], the clinical trial data are inconclusive $[15,38]$. While some studies have shown no effect on the recurrence rate of UTIs [48-50], others have shown a reduction in the number of potential pathogenic bacteria and yeasts colonising the vagina in healthy women [51] or a reduction in the recurrence of UTI when administering Lactobacillus rhamnosus GR-1 and Lactobacillus fermentum
RC-14 in women with a history of UTI [52]. Beerepoot et al. [53] reported a reduction in the mean number of UTIs in the previous year from 6.8 to 3.3 in postmenopausal women taking Lactobacillus rhamnosus GR-1 and Lactobacillus fermentum RC-14 twice daily for 12 months, whereby the predefined non-inferiority threshold was not reached compared to long-term treatment with trimethoprim-sulfamethoxazole. However, unlike trimethoprim-sulfamethoxazole, Lactobacilli do not increase antibiotic resistance.

Our study lacks a control group. Stapleton [28] reported that in 100 premenopausal women who initially received Lactobacillus crispatus CTV-05 or placebo daily for 5 days, then once weekly for 10 weeks, recurrent UTIs occurred in $15 \%$ of women receiving the probiotic compared with $27 \%$ of women receiving placebo. The absolute numbers of UTI outcome in the probiotic group were similar to our results at month two in the CC group, where $16.7 \%$ had a recurrent UTI. This supports our findings. They could also show that women who received probiotic achieved a high-level Lactobacillus crispatus vaginal colonization pattern, which was not shown in other studies with different strains.

However, the treatment with lactic acid gel bypasses the indeterminate search for a suitable probiotic strain and risk of insufficient colonisation. Ideally, the negative feedback loop during rUTIs, in which pathogens such as $E$. coli increase $\mathrm{pH}$-levels, is interrupted and reversed by the treatment with lactic acid.

The presented observational study offers valuable insights from real-world treatment of a highly prevalent urogynecological disorder. Study results suggest that the treatment with vaginal lactic acid gel could prevent and delay the occurrence of urinary tract infections. The assessment of the results was consistent between patients and treating physicians. This further substantiates the results of a beneficial 
effect of preventing and delaying rUTIs with lactic acid gel treatment.

In uncomplicated cases of recurrent UTIs, the intermittent use of a vaginal lactic acid gel for relapse prevention could therefore reduce the excessive long-term use of antibiotics.

The study is limited in some regards. Treatment/observational time was limited to 4 months to achieve the highest possible compliance of the patients in filling out the diaries. Nevertheless, with a mean of four UTIs in the last 12 months, an observation period of 4 months is an adequate period to evaluate improvements. However, an extension of the period to 6 or 12 months would be preferable. Further trials and studies are still warranted to improve our understanding of ideal treatment options.

\section{Conclusion}

Intermittent short courses of intravaginal treatment with lactic acid gel (KadeFungin ${ }^{\circledR}$ Milchsäurekur), applied 2-3 days after each menstruation, may be beneficial for the resilience against uropathogens and reduce the rate of reinfection in UTI-prone women. Intravaginal treatment with the lactic acid gel was overall very well tolerated by patients and was generally assessed very positively by the patients. The physicians' assessments corroborated these findings.

Acknowledgements The authors are grateful for the support of the participating centres. We thank co.faktor ${ }^{\circledR} \mathrm{GmbH}$, Berlin, Germany for support with writing the first draft manuscript and TH (Pharmalog Institut für klinische Forschung $\mathrm{GmbH}$, Ismaning, Germany) for data managing.

Funding The study was funded by Dr. Kade Pharmazeutische Fabrik $\mathrm{GmbH}$, Berlin, Germany (https://www.kade.de). The funder played a role in study design, decision to publish and preparation of the manuscript. However, the funder had no role in data collection and analysis.

Availability of data and material All relevant data are within the manuscript.

\section{Declarations}

Conflict of interest Author R Diebold is an employee of DR. KADE Pharmazeutische Fabrik GmbH, Berlin, Germany and received support in form of salary. The authors B Schopf and H Stammer are employees of the Clinical Research Organistation Pharmalog Institut für klinische Forschung GmbH, which was contracted by DR. KADE. The scientific study coordinator W Mendling received honorarium for this work as well as speaker honoraria at scientific training events organized by the funder.

Ethics approval Due to the observational character of the study, no formal ethic vote was necessary. In accordance with article 15(1) of the model professional code for physicians in Germany, all study-relevant documents were approved by the ethic committee (ethics commission of the Bavarian medical association, Munich).
Consent to participate Prior to inclusion, a written informed consent was obtained from each participant.

Consent for publication All authors agreed to the publication.

Open Access This article is licensed under a Creative Commons Attribution 4.0 International License, which permits use, sharing, adaptation, distribution and reproduction in any medium or format, as long as you give appropriate credit to the original author(s) and the source, provide a link to the Creative Commons licence, and indicate if changes were made. The images or other third party material in this article are included in the article's Creative Commons licence, unless indicated otherwise in a credit line to the material. If material is not included in the article's Creative Commons licence and your intended use is not permitted by statutory regulation or exceeds the permitted use, you will need to obtain permission directly from the copyright holder. To view a copy of this licence, visit http://creativecommons.org/licenses/by/4.0/.

\section{References}

1. Foxman B (2014) Urinary tract infection syndromes: occurrence, recurrence, bacteriology, risk factors, and disease burden. Infect Dis Clin N Am 28(1): 1-13

2. Deutsche Gesellschaft für Urologie (DGU), Epidemiologie, Diagnostik, Therapie, Prävention und Management unkomplizierter, bakterieller, ambulant erworbener Harnwegsinfektionen bei erwachsenen Patienten. S-3 Leitlinie Langfassung [AWMFRegister-Nr. 043/044]. Stand: 30.04.2017

3. O'Brien VP et al (2016) Drug and vaccine development for the treatment and prevention of urinary tract infections. Microbiol Spectr 4(1):589-646. https://doi.org/10.1128/microbiolspec.UTI-0013-2012

4. Wawrysiuk S et al (2019) Prevention and treatment of uncomplicated lower urinary tract infections in the era of increasing antimicrobial resistance-non-antibiotic approaches: a systemic review. Arch Gynecol Obstet 300(4):821-828

5. Naber KG et al (2008) Surveillance study in Europe and Brazil on clinical aspects and antimicrobial resistance epidemiology in females with cystitis (ARESC): implications for empiric therapy. Eur Urol 54(5):1164-1178

6. Bonkat $\mathrm{G}$ et al (2017) Urological infections. EAU Guidelines London: European Association of Urology, pp 857-920

7. O'Mahony $\mathrm{C}$ et al (2008) Commensal-induced regulatory $\mathrm{T}$ cells mediate protection against pathogen-stimulated NF-kappaB activation. PLoS Pathog 4(8):e1000112

8. Smith AL et al (2018) Treatment and prevention of recurrent lower urinary tract infections in women: a rapid review with practice recommendations. J Urol 200(6):1174-1191

9. Wagenlehner F et al (2018) Social and economic burden of recurrent urinary tract infections and quality of life: a patient webbased study (GESPRIT). Expert Rev Pharmacoecon Outcomes Res 18(1):107-117

10. Stapleton AE (2016) The vaginal microbiota and urinary tract infection. Microbiol Spectr 4(6):79-86. https://doi.org/10.1128/ microbiolspec.UTI-0025-2016

11. Bauer HW (1998) Epidemiologie, urogenitale infektionen. Springer Verlag

12. Enzyklopädie, H., Hagers enzyklopädie. Dih-Eti. Vol. 6.

13. Ejrnaes K (2011) Bacterial characteristics of importance for recurrent urinary tract infections caused by Escherichia coli. Dan Med Bull 58(4):B4187

14. Hanson L et al (2016) Probiotics for treatment and prevention of urogenital infections in women: a systematic review. J Midwifery Womens Health 61(3):339-355 
15. Schwenger EM, Tejani AM, Loewen PS (2015) Probiotics for preventing urinary tract infections in adults and children. Cochrane Database Syst Rev 12:73-99. https://doi.org/10.1002/14651858

16. Swidsinski A et al (2012) Positive effects of local therapy with a vaginal lactic acid gel on dysuria and E.coli bacteriuria question our current views on recurrent cystitis. Arch Gynecol Obstet 285(6):1619-1625

17. Instruction for use KadeFungin ${ }^{\circledR}$ Milchsäurekur, September 2018. Available from: https://www.kade.de/media/Produkte/Gebrauchsi nformationen/kadefungin-milchsaeurekur-GI-20200427.pdf. Accessed 14 Mar 2021

18. World Medical Association, Declaration of Helsinki. Ethical principles for medical research involving human subjects. https:// www.wma.net/wp-content/uploads/2018/07/DoH-Oct2008.pdf, 2008. Accessed 14 Mar 2021

19. International Organization for Standardization/Technical Committee 194(ISO/TC194), Clinical investigation of medical devices for human subjects: Good clinical practice. Second edition February 2011 (ISO 14155:2011). Official Journal of the European Union (OJ). 2012/C123/02:2012-04-27

20. Bundesärztekammer, (Muster-)Berufsordnung für die in Deutschland tätigen Ärztinnen und Ärzte-MBO-Ä 1997-in der Fassung der Beschlüsse des 121. Deutschen Ärztetages 2018 in Erfurt geändert durch Beschluss des Vorstandes der Bundesärztekammer am 14.12.2018

21. European Commission. Guidelines on Medical Devices-Clinical Investigations: Serious Adverse Event Reporting under Directives 90/385/EEC and 93/42/EEC. MEDDEV 2.7/3 revision 3 (May 2015) Available from: https://ec.europa.eu/docsroom/documents/13053/attac hments/1/translations/en/renditions/pdf. Accessed 14 Mar 2021

22. Hintze J (2011) PASS 11. NCSS, LLC. Kaysville, Utah, USA. https://www.ncss.com. Accessed 14 Mar 2021

23. Czaja CA et al (2009) Prospective cohort study of microbial and inflammatory events immediately preceding Escherichiacoli recurrent urinary tract infection in women. J Infect Dis 200(4):528-536

24. Bruce AW et al (1973) Recurrent urethritis in women. Can Med Assoc J 108(8):973-976

25. Gupta $\mathrm{K}$ et al (1998) Inverse association of $\mathrm{H}_{2} \mathrm{O}_{2}$-producing lactobacilli and vaginal Escherichia coli colonization in women with recurrent urinary tract infections. J Infect Dis 178(2):446-450

26. O'Hanlon DE, Moench TR, Cone RA (2013) Vaginal pH and microbicidal lactic acid when lactobacilli dominate the microbiota. PLoS ONE 8(11):e80074

27. Hudson PL et al (2020) Effect of vaginal lactobacillus species on Escherichiacoli growth. Female Pelvic Med Reconstr Surg 26(2):146-151

28. Stapleton AE et al (2011) Randomized, placebo-controlled phase 2 trial of a lactobacillus crispatus probiotic given intravaginally for prevention of recurrent urinary tract infection. Clin Infect Dis 52(10):1212-1217

29. Pfau A, Sacks T (1981) The bacterial flora of the vaginal vestibule, urethra and vagina in premenopausal women with recurrent urinary tract infections. J Urol 126(5):630-634

30. Tachedjian $\mathrm{G}$ et al (2017) The role of lactic acid production by probiotic Lactobacillus species in vaginal health. Res Microbiol 168(9):782-792

31. Alakomi HL et al (2000) Lactic acid permeabilizes Gram-negative bacteria by disrupting the outer membrane. Appl Environ Microbiol 66(5):2001-2005

32. Boeke AJ et al (1993) Effect of lactic acid suppositories compared with oral metronidazole and placebo in bacterial vaginosis: a randomised clinical trial. Genitourin Med 69(5):388-392

33. Andersch B et al (1986) Treatment of bacterial vaginosis with an acid cream: a comparison between the effect of lactate-gel and metronidazole. Gynecol Obstet Invest 21(1):19-25
34. Decena DCD et al (2006) Metronidazole with lactacyd vaginal gel in bacterial vaginosis. J Obstet Gynaecol Res 32(2):243-251

35. Andersch B et al (1990) Bacterial vaginosis and the effect of intermittent prophylactic treatment with an acid lactate gel. Gynecol Obstet Invest 30(2):114-119

36. Plummer EL et al (2021) Lactic acid containing products for bacterial vaginosis and their impact on the vaginal microbiota: a systematic review. PLoS ONE. https://doi.org/10.1371/journal.pone.0246953

37. Tidbury FD et al (2020) Non-antibiotic treatment of bacterial vaginosis-a systematic review. Arch Gynecol Obstet 303:1-9

38. Barrons R, Tassone D (2008) Use of Lactobacillus probiotics for bacterial genitourinary infections in women: a review. Clin Ther 30(3):453-468

39. Falagas ME et al (2006) Probiotics for prevention of recurrent urinary tract infections in women: a review of the evidence from microbiological and clinical studies. Drugs 66(9):1253-1261

40. Ng QX et al (2018) Use of Lactobacillus spp to prevent recurrent urinary tract infections in females. Med Hypotheses 114(9):49-54

41. Reid G, Bruce AW (2006) Probiotics to prevent urinary tract infections: the rationale and evidence. World J Urol 24(1):28-32

42. Borges S, Silva J, Teixeira P (2014) The role of lactobacilli and probiotics in maintaining vaginal health. Arch Gynecol Obstet 289(3):479-489

43. Heinemann $C$ et al (2000) Purification and characterization of a surface-binding protein from Lactobacillus fermentum RC-14 that inhibits adhesion of Enterococcus faecalis 1131. FEMS Microbiol Lett 190(1):177-180

44. Velraeds MM et al (1996) Inhibition of initial adhesion of uropathogenic Enterococcus faecalis by biosurfactants from Lactobacillus isolates. Appl Environ Microbiol 62(6):1958-1963

45. Trivedi D et al (2013) Partial purification and characterization of a bacteriocin $\mathrm{dt} 24$ produced by probiotic vaginal Lactobacillus brevis dt 24 and determination of its anti-uropathogenic Escherichiacoli potential. Probiotics Antimicrob Proteins 5(2):142-151

46. Leccese Terraf MC et al (2017) In vitro effect of vaginal Lactobacilli on the growth and adhesion abilities of uropathogenic Escherichiacoli. Arch Microbiol 199(5):767-774

47. Juárez Tomás MS et al (2003) Growth and lactic acid production by vaginal Lactobacillusacidophilus CRL 1259, and inhibition of uropathogenic Escherichiacoli. J Med Microbiol 52(12):1117-1124

48. Baerheim A, Larsen E, Digranes A (1994) Vaginal application of lactobacilli in the prophylaxis of recurrent lower urinary tract infection in women. Scand J Prim Health Care 12(4):239-243

49. Czaja CA et al (2007) Phase I trial of a Lactobacillus crispatus vaginal suppository for prevention of recurrent urinary tract infection in women. Infect Dis Obstet Gynecol. https://doi.org/10.1155/2007/35387

50. Kontiokari $\mathrm{T}$ et al (2001) Randomised trial of cranberry-lingonberry juice and Lactobacillus GG drink for the prevention of urinary tract infections in women. BMJ 322(7302):1571-1573

51. Reid G et al (2003) Oral use of Lactobacillus rhamnosus GR-1 and Lfermentum RC-14 significantly alters vaginal flora: randomized, placebo-controlled trial in 64 healthy women. FEMS Immunol Med Microbiol 35(2):131-134

52. Reid G, Bruce AW, Taylor M (1992) Influence of three-day antimicrobial therapy and Lactobacillus vaginal suppositories on recurrence of urinary tract infections. Clin Ther 14(1):11-16

53. Beerepoot MA et al (2012) Lactobacilli vs antibiotics to prevent urinary tract infections: a randomized, double-blind, noninferiority trial in postmenopausal women. Arch Intern Med 172(9):704-712

Publisher's Note Springer Nature remains neutral with regard to jurisdictional claims in published maps and institutional affiliations. 